\title{
Studi Eksperimen Pengaruh Pencampuran Gas HHO pada Gas LPG Secara Premixed Terhadap Bentuk Nyala Api Bunsen Burner
}

\author{
Agus Harianto $^{1 *}$, Djoko Sungkono Kawano ${ }^{2 *}$ \\ 1) Pengajar di Jurusan Teknik Mesin, Universitas Antakusuma Pangkalan Bun \\ Kampus UNTAMA, Pangkalan Bun 74112 \\ e-mail: 1) agus.harianto80@gmail.com \\ 2) Pengajar di Jurusan Teknik Mesin, Institut Teknologi Sepuluh Nopember Surabaya \\ Kampus ITS, Sukolilo, Surabaya 60111
}

\begin{abstract}
Intisari-Bentuk nyala api berguna untuk dasar informasi desain tungku pemanas pada boiler maupun kompor, sehingga dapat diketahui titik terpanas pembakaran. Kualitas pembakaran dapat ditingkatkan dengan berbagai cara. Salah satu cara yaitu mencampur gas LPG dengan gas HHO. Penelitian ini bertujuan untuk mengatahui bentuk nyala api bunsen burner dengan menggunakan campuran gas HHO dengan gas LPG. Penelitian ini dilakukan dengan metode eksperimen dan pencampuran gas HHO dengan gas LPG secara premixed pada bunsen burner. Variasi pencampuran gas HHO adalah $0 \%$, 25\%, dan 50\% terhadap gas LPG. Dari penelitian diketahui perbedaan bentuk api dari panjang dan lebar nyala api.
\end{abstract}

Kata kunci-Gas HHO, gas LPG, Premixed, Temperatur, Bentuk api.

\section{PENDAHULUAN}

Berbagai langkah untuk memenuhi kebutuhan energi menjadi topik penting seiring dengan semakin berkurangnya sumber energi fosil yang ada. Sistem energi yang ada sekarang sebagian besar masih dihasilkan dari proses pembakaran bahan bakar pada pembangkit listrik tenaga uap, gas serta uap dan gas. Demikian pula halnya dengan sistem transportasi, serta berbagai proses di industri yang membutuhkan sumber panas dari hasil pembakaran bahan bakar di dalam ruang bakar. Kajian tentang pembakaran sangat mempengaruhi penghematan penggunaan bahan bakar yang semakin langka. Kajian eksperimental maupun kajian teoritis tentang pembakaran telah banyak dilakukan untuk lebih memahami fenomena pembakaran [1-3]. Simulasi dengan berbagai macam metode numerik semakin banyak dilakukan didukung kemajuan di bidang teknologi informasi. Langkah-langkah tersebut pada dasarnya bertujuan untuk memperoleh metode baru membakar bahan bakar dengan lebih hemat, bersih dan stabil, sehingga pada akhirnya pemenuhan kebutuhan energi yang diperoleh dari proses pembakaran dapat lebih terjamin.

Berbagai macam metode telah diteliti baik dari aspek kuantitas dan kualitas aliran campuran udara dan bahan bakar, pencampuran bahan bakar fosil dan bahan bakar terbarukan maupun rekayasa peralatan burner. Dari aspek campuran bahan bakar fosil dan bahan bakar terbarukan, dengan penambahan gas hidrogen pada gas LPG, maka panjang nyala api semakin berkurang, lebar nyala api bertambah, namun temperatur nyala api semakin meningkat (Zhen et al.,[5]). Penelitian yang belum dilakukan adalah penambahan gas HHO pada gas LPG. Dari penelitian ini diharapkan dapat diketahui perbedaan bentuk nyala api pada bunsen burner.

\section{METODE}

Pada penelitian ini, variasi campuran gas $\mathrm{HHO}$ pada gas LPG adalah $\alpha=0 \%, 25 \%$, dan $50 \%$ volume flowrate dengan persamaan: $\alpha=\mathrm{H} \_2 /\left(\mathrm{H} \_2+\mathrm{LPG}\right)$ sehingga didapat: $\alpha 0 \%=$ gas LPG 0,5 liter permenit dan gas $\mathrm{HHO} 0$ liter per menit

$\alpha 25 \%=$ gas LPG 0,375 liter per menit dan gas $\mathrm{HHO}$ 0,125 liter per menit

$\alpha 50 \%=$ gas LPG 0,25 liter per menit dan gas HHO 0,25 liter per menit.

Pencampuran gas HHO, gas LPG, dan oksigen terjadi secara premixed pada pembakaran bunsen burner. Volume oksigen tidak diukur, oksigen diambil dari udara bebas dan tercampur secara premixed dengan bahan bakar pada ventilasi udara bunsen burner. Gas LPG menggunakan LPG $3 \mathrm{~kg}$ yang dipasarkan oleh Pertamina unit Gresik dengan komposisi volume propane 49,06\% dan volume butane $50,81 \%$.

Pengukuran distribusi temperatur menggunakan delapan termokopel yang disusun sejajar dengan jarak 3 $\mathrm{mm}$, dan incremental $3 \mathrm{~mm}$ ke atas sampai di ketinggian api. Pengukuran dilakukan dengan cara menggunakan termokopel Type K (range pengukuran: $0-1275$ oC). Output tegangan analog dari termokopel dikonversi kedalam bentuk digital oleh ADC data Logger Type $128 \mathrm{C}$ merek Omega kemudian ditransfer ke dalam komputer menggunakan Software peralatan ADC data logger merek omega. Dengan Software tersebut signal digital diterjemahkan kedalam bentuk Temperatur (oC). Data tersebut dicatat dan dimasukkan ke dalam software ORIGINLAB untuk mendapatkan kontur isothermal. Dari kontur isothermal akan diolah menjadi distribusi rata-rata temperatur menggunakan persamaan sebagai berikut: 


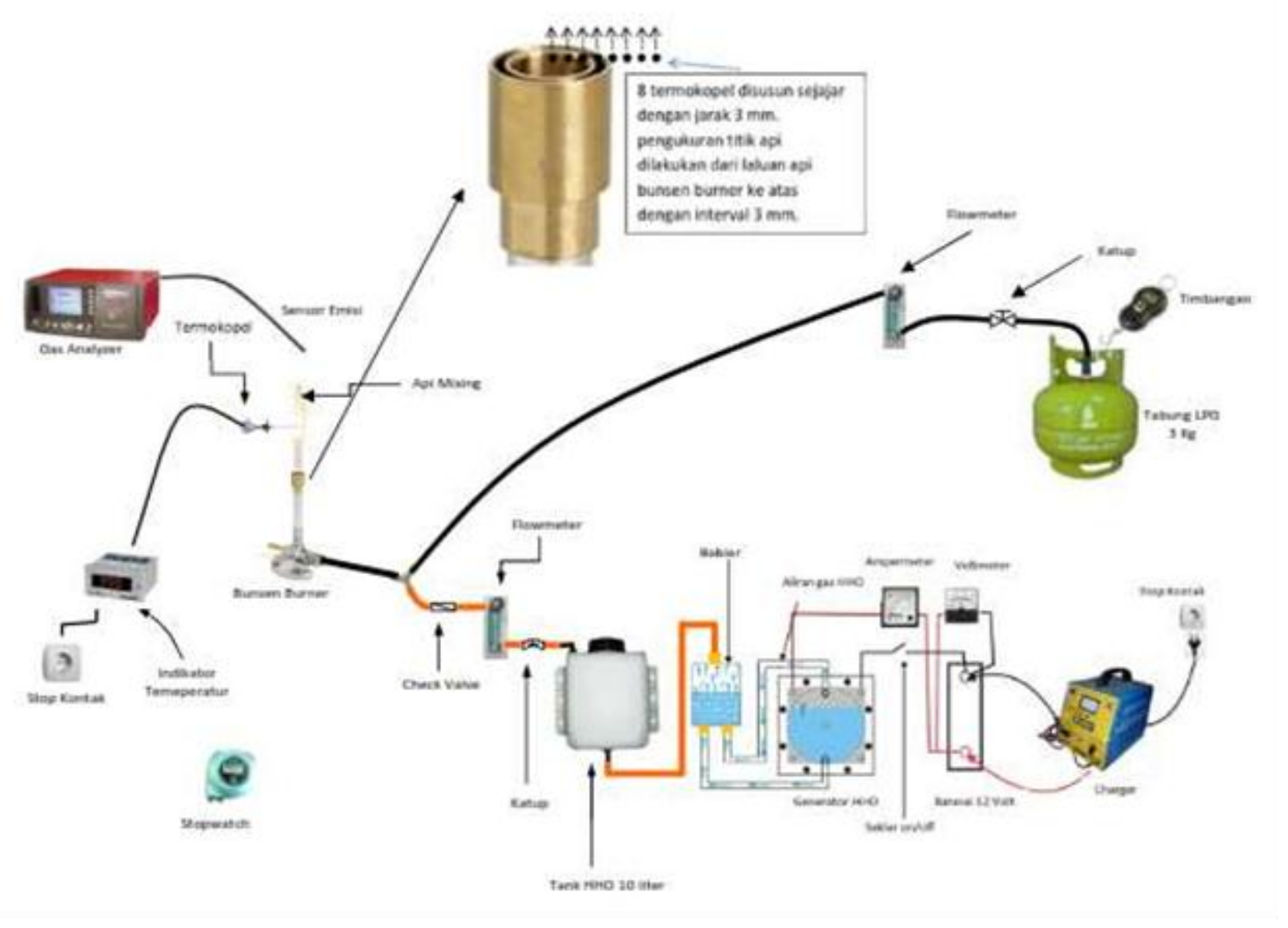

Gambar 1. Skema Penelitian

dimana :

$$
\begin{array}{ll}
\mathrm{T}_{-}(\text {rata-rata }) & =\frac{(\text { AxT }) \text { total }}{\text { Atotal }} \\
\mathrm{A}_{\text {tot }} & =\sum_{\mathrm{i}=1}^{\mathrm{n}}\left[\pi\left(\mathrm{ro}_{\mathrm{i}}^{2}-\mathrm{ri}_{\mathrm{i}}^{2}\right)\right] \\
(\mathrm{A} \mathrm{x} \mathrm{T})_{\text {tot }} & =\sum_{\mathrm{i}=1}^{\mathrm{n}}\left[\pi\left(\mathrm{ro}_{\mathrm{i}}^{2}-\mathrm{ri}_{\mathrm{i}}^{2}\right) \times \mathrm{T}_{\mathrm{i}}\right]
\end{array}
$$

\section{Keterangan:}

$\mathrm{Ti}=$ temperatur rata - rata diantara 2 garis isothermal

ro $=$ jari-jari luar

ri $=$ jari-jari dalam

Pengukuran daya bahan bakar pada bunsen burner dilakukan dengan cara mengukur volume flowrate bahan bakar gas LPG dan gas HHO dengan persamaan sebagai berikut:

$$
P=\frac{m_{f} \times E}{t}(k J / s)
$$

Keterangan:

$\mathrm{mf}=$ Konsumsi bahan bakar selama pengukuran $(\mathrm{kg})$

$\mathrm{E}=$ Nilai kalor netto bahan bakar $(\mathrm{kJ} / \mathrm{kg})$ pada tabel 2.5

$$
\mathrm{t} \quad=\text { Waktu pengukuran }(\mathrm{s})
$$

\section{HASIL DAN PEMBAHASAN}

\section{A. Bentuk Api dan kontur Isothermal}

Pada gambar 2 dapat dilihat bahwa semakin besar campuran gas HHO pada gas LPG, maka panjang nyala api bunsen burner semakin berkurang, dan lebar nyala api semakin bertambah.

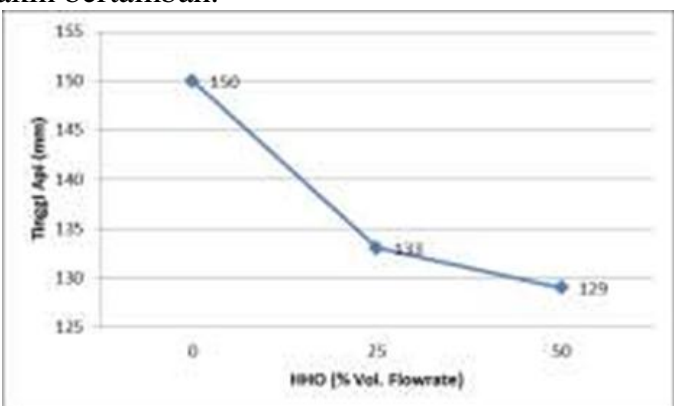

Gambar 3. Grafik pencampuran gas HHO terhadap tinggi nyala api 


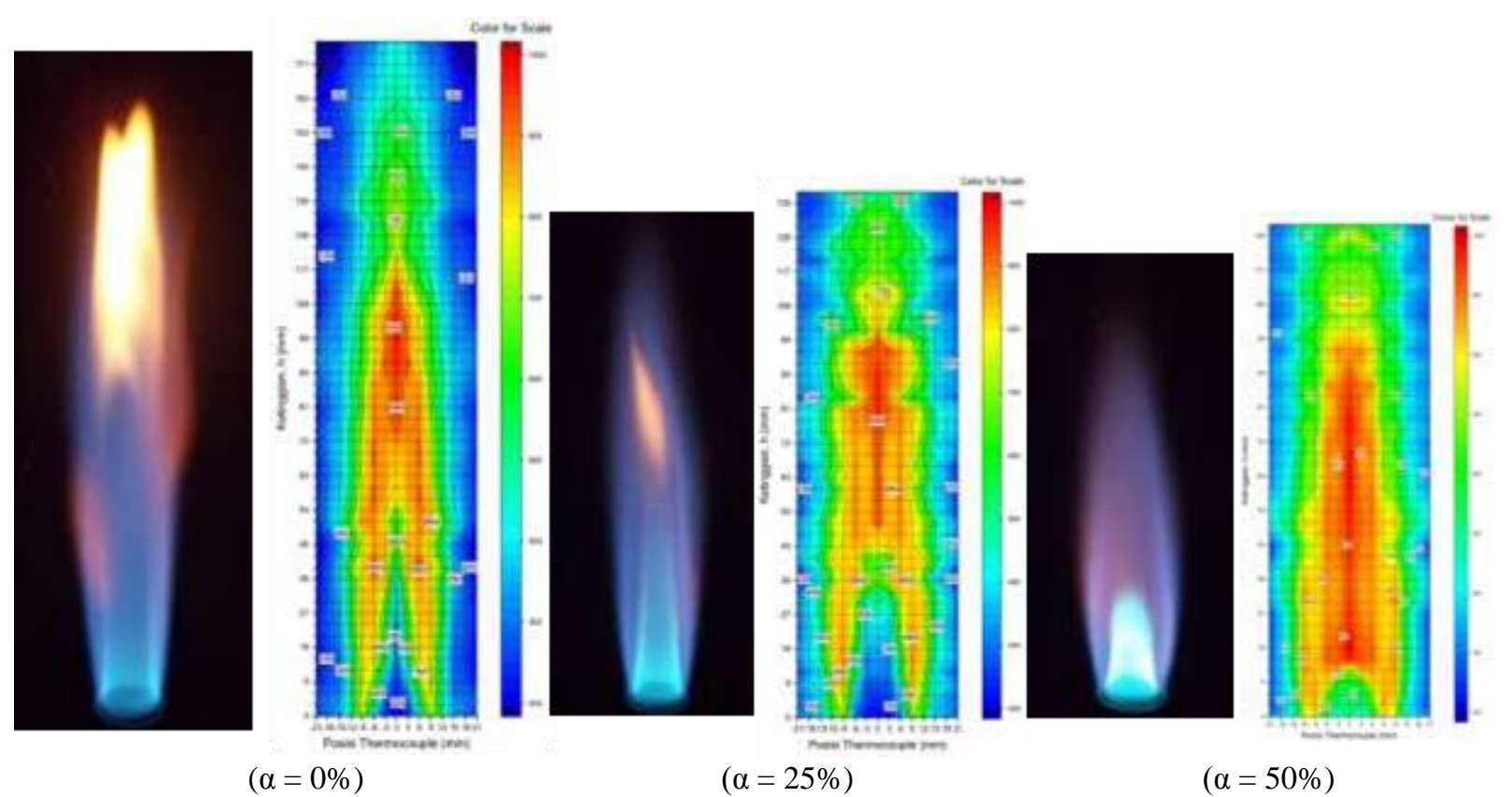

Gambar 2. Bentuk api dan kontur isothermal premixed HHO 0\%, 25\%, dan $50 \%$ pada LPG

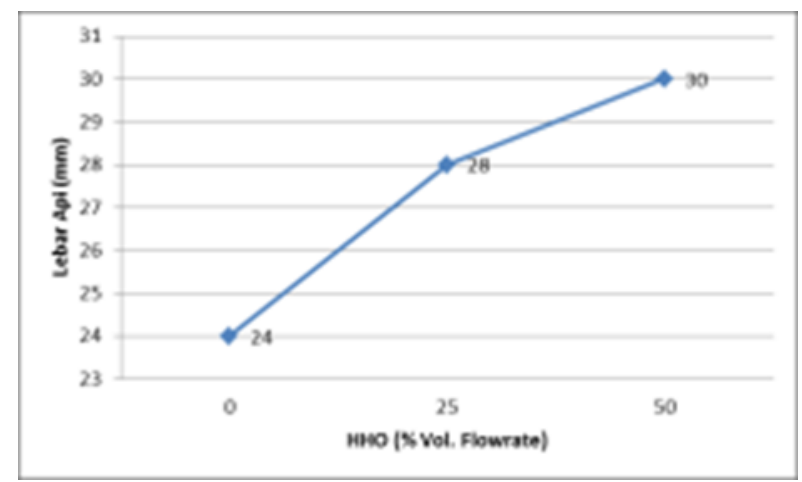

\section{Gambar 4. Grafik pencampuran gas HHO terhadap lebar nyala api}

Hal ini sesuai dengan persamaan panjang nyala api premixed yang diusulkan oleh Rokke. Persamaan Rokke menunjukkan korelasi antara panjang nyala yang sebanding dengan fraksi massa bahan bakar. Semakin turun nilai AFR berarti fraksi massa bahan bakar semakin tinggi sehingga panjang nyala api juga meningkat, (Rokke [4]). Juga sejalan dengan penelitian Zhen dkk, bahwa semakin besar campuran volume flowrate gas hidrogen pada gas LPG, maka panjang nyala api semakin menurun, (Zhen et al.,[5]).

\section{KESIMPULAN}

Dari penelitian ini dapat disimpulkan bahwa Pencampuran gas HHO 50\% pada gas LPG, maka panjang nyala api pada pembakaran bunsen burner berkurang sebesar $14 \%$, dan lebar nyala api semakin bertambah sebesar $25 \%$.

\section{UCAPAN TERIMA KASIH}

Penghargaan dan ucapan terimakasih kepada Istri dan anak tercinta, kedua orang tua, keluarga, dan kepada Prof. Dr. Ir. H. Djoko Sungkono K, M.Eng.Sc.

\section{DAFTAR PUSTAKA}

[1] Yunh-Cheng Chen, Munki Kim, Jeongjae Han, Sangwook Yun dan Youngbin Yoon, 'Analysis of flame surface normal and curvature measured in turbulent Premixed stagnation-point flames with crossed-plane tomography, Proceeding of the Combustion Institute, 31 (2007) hal. 1327-1335

[2] [2] Eduardo Fernandez-Tarrazo, Marcos Vera dan Amable Linan, "Liftoff and blowoff of a diffusion flame between parallel streams of fuel and air", Combustion and Flame 144 (2006) hal 261-276

[3] Andres A. Chaparro dan Baki M. Cetegen, Blowoff Characteristics of Bluffbody stabilized conical premixed flames under upstream velocity modulation, Combustion and Flame Vol 144, Issues 1-2, (2006) hal. 318-335

[4] Nils A Rokke, 'A Study of Partially Premixed Unconfined Propane Flames, Combustion and Flame 97, 1986, hal 88-106.

[5] Zhen, H.S., Cheung, C.S., Leung, C.W., Choy, Y.S., "Effect of Hydrogen Concentration on the Emission and Heat Transfer of a Premixed LPG-Hydrogen Flame", Int. Journal of Hydrogen Energy, Vol.37, 2012, hal. 6097-6105. 
HALAMAN INI SENGAJA DIKOSONGKAN 